\title{
The Mixed Conception of Corrective Justice $^{\dagger}$
}

\author{
Jules L. Coleman*
}

In contemporary tort theory, both economists and moralists advance the view that tort law can be understood as the embodiment of one fundamental, overarching principle. For economists it is the principle of efficiency. ${ }^{1}$ For some moralists, like George Fletcher, it is the principle of reciprocity of risk. ${ }^{2}$ While for others, like Richard Epstein, it is the principle of causal responsibility. ${ }^{3}$ In contrast, I reject the idea that the practice can be understood as a unified whole and argue that tort law implements a variety of different principles and policies. ${ }^{4}$ Some of these are economic in nature, others moral. In this Essay, I develop the underlying moral principle involved in tort law-the principle of corrective justice. ${ }^{5}$

In a recent essay ${ }^{6}$ I presented a fully developed account of the principle of corrective justice as I have understood and defended it. Aspects of that account have been the target of powerful criticisms advanced by Stephen Perry. ${ }^{7}$ Largely as a consequence of these objections, I have

† ${ }^{\circ}$ (1992) Jules L. Coleman. All rights reserved.

*John A. Garver Professor of Jurisprudence and Philosophy, Yale Law School. This Essay is drawn from a chapter in Jules L. Coleman, Risks and Wrongs (Cambridge University Press, forthcoming 1992).

1. William M. Landes \& Richard A. Posner, The Economic Structure of Tort Law (1987); Richard A. Posner, The Economics of Justice (1981); Richard A. Posner, The Concept of Corrective Justice in Recent Theories of Tort Law, $10 \mathrm{~J}$. Legal Stud. 187 (1981).

2. George Fletcher, Fairness and Utility in Tort Theory, 85 Harv. L. Rev. 537 (1972).

3. Richard A. Epstein, Nuisance Law: Corrective Justice and its Utilitarian Constraints, 8 J. Legal Stud. 49 (1979); Richard A. Epstein, A Theory of Strict Liability, 2 J. Legal Stud. 151 (1973).

4. Jules L. Coleman, Markets, Morals and the Law (1988); Jules L. Coleman, Moral Theories of Torts: Their Scope and Limits, 1 Law \& Phil. 371 (1982); Jules L. Coleman, Justice and the Argument for No-Fault, 3 Soc. Theory \& Prac. 161 (1974); Jules L. Coleman, On the Moral Argument for the Fault System, 71 J. Phil. 473 (1974).

5. In what follows, I present a particular conception of corrective justice. Like any conception, this one will be controversial and contestable. A central question the reader will want answered is: by what criteria are competing conceptions of corrective justice to be evaluated? This is an especially important question, since even among tort theorists who advance the view that to some extent at least tort law is a matter of corrective justice, there is virtually no agreement about what corrective justice requires. In the argument that follows, I will defend my version of corrective justice and comment on how various conceptions are to be evaluated. Ultimately, no defense of a conception of corrective justice is satisfactory in the absence of a foundation for it. Of course, different views exist about what counts as an appropriate foundation for a principle of justice. Differences of opinion even exist about whether foundational arguments are possible. On these matters, I am partial to the wisdom of my teacher, Joel Feinberg, that progress can be made on the penultimate questions in philosophy even as the ultimate ones remain unresolved.

6. See Jules L. Coleman, Tort Law and the Demands of Corrective Justice, 67 Ind. L.J. 349 (1992). (1992).

7. See Stephen R. Perry, Comment on Coleman: Corrective Justice, 67 Ind. L.J. 381 
reconsidered the content of corrective justice as a moral ideal. This Essay develops a new conception of corrective justice.

\section{INTRODUCTION}

Suppose that you are extremely wealthy. Your wealth exceeds that of the Rockefellers. Assume, moreover, there is no possible principle of distributive justice with which your current wealth is compatible. In other words, you have more than that to which you would be entitled under even the most inegalitarian, but defensible, principle of distributive justice. Suppose my situation is just the opposite. I am dreadfully poor. I have less than that to which I would be entitled under even the most inegalitarian, but defensible, conception of distributive justice. Thus, neither of our positions can be sustained under any plausible theory of distributive justice. As luck would have it, one day I ram my car into yours causing you to endure a significant financial setback. You are now less wealthy than before, and, a fortiori, closer to the demands of distributive justice. Just to complete the story, suppose somehow the wealth you lose is transferred to me. Perhaps an auto accident is an implausible way to transfer wealth. In that case, simply suppose I defraud you of your money.

The question is whether you have a right to repair or to compensation against me. After all, you have no right to your wealth under the relevant principle of distributive justice; and, if you have no right to your wealth, how can you have a right to have it restored when I reduce it? We can imagine a range of reasons for compensating you which have nothing to do with justice or right. For example, the possibility of securing compensation gives you a reason for suing me. Further, suing me for negligence or wrongdoing also privately enforces safe driving. Compensating you increases the cost of my negligence and thus provides me with an incentive to drive safely. Can compensating you be a matter of justice as well, and, if so, under what principle of justice?

It may be good social policy to compensate you and in so doing to recreate or protect a patently unjust distribution of wealth. This may seem like a price worth paying to create the right incentives: yours to sue, mine to drive safely. I suggest, however, that compensating you can also be a matter of justice. Justice may require your entitlement to repair even if it reinforces less than wholly just holdings. One consequence of my view is that justice may sustain an unjust distribution of wealth. I believe one must be committed to this if your claim to repair against me can be a matter of justice in those cases in which the underlying entitlement cannot itself be defended as required by justice. ${ }^{8}$ If sustaining or protecting a less than fully

8. The view of corrective justice I put forward is partially motivated by two pretheoretical commitments that I am prepared ultimately to abandon, but which can be abandoned only at some cost to the plausibility of one's theory. These are: (1) the belief that your claim to compensation in the case I have constructed can be a matter of justice as well as efficiency; and (2) the New Zealand plan for allocating accident costs may be wrongheaded, unworkable, maybe even inefficient, but it does not constitute one gigantic affront to the principle of corrective justice. I will have more to say about the New Zealand plan and similar liability schemes when we turn our attention to institutional embodiments of the principle of corrective justice, See Coleman, supra note *. For now, I want to confine the discussion to the principle 
just distribution of wealth or resources sometimes can be a matter of justice, it cannot be a matter of distributive justice. Then what sort of justice is it?

The answer is corrective justice. Before I say anything more about the demands of corrective justice and the way those demands fit with those of distributive justice, it is important to distinguish between endorsing injustice and implementing a policy that has the effect of sustaining or protecting injustice. The difference goes to the point or purpose of an institution or the intentions of the agents within it. Meeting the demands of corrective justice may recreate or sustain an unjust distribution of holdings, but endorsing distributive injustice is not part of the point of corrective justice. Of course, if meeting the demands of corrective justice entrenches distributive injustice, that might serve as a reason against devoting substantial resources to meeting the demands of corrective justice. ${ }^{9}$

\section{The Annulment Conception of Correctrve Justice}

The first conception of corrective justice I want to discuss-the one I previously have defended in my writings-is the annulment thesis. ${ }^{10}$ According to the annulment thesis, the goal of corrective justice is to eliminate, rectify, or annul wrongful (or unjust) losses. ${ }^{11}$ Corrective justice,

of corrective justice itself.

9. For an extensive account of the demands of corrective justice and of the ways in which corrective and distributive justice connect to one another, see Coleman, supra note *.

10. This is the conception of corrective justice I formerly defended, but no longer do. My most detailed defense of it appears in Coleman, supra note 6.

11. Three limitations on this principle need to be mentioned. First, not every loss, however wrongfully created, is the concern of corrective justice. Suppose losses are wrongful if they are the result of negligent or wrongful interference with a person's legitimate interests. Then whenever a person has suffered a wrongful loss in this sense that person will have the makings of a claim in corrective justice to repair. But, there are many losses that an individual suffers at the hands of others. Although they may fall within the ambit of morality, they are nevertheless outside the scope of justice. So what we will need is a theory about which interests of the person fall within the scope of corrective justice. That theory will not itself be part of corrective justice, but will instead set its boundaries. The analogous problem in torts is the problem of specifying the range of compensable harms or protected interests. Even when we know what the principles and standards of recovery in torts are, we may still have questions about the sorts of losses for which victims can seek repair, or the kinds of interests the law seeks to protect.

Second, corrective justice is concerned fundamentally with the gains and losses one person causes another. I suppose it is possible to wrong oneself and therefore to impose wrongful losses upon oneself. Similarly, it may be possible to secure wrongful gains at no one's expense. These gains and losses are not primarily the concern of corrective justice, though in my view there may be no reason to exclude them entirely from its ambit.

Finally, the analysis of corrective justice in this Essay focuses primarily on wrongful losses and the institutions made available for rectifying them. Rectifying wrongful losses is central to tort law in a way in which rectifying wrongful gains is not. The institution of restitution concerns itself primarily with wrongful gains. Restitution damages in contracts have a similar purpose. It is not part of my view that there is anything like a one-to-one mapping of principles of justice to legal institutions: retributive justice to the criminal law, corrective justice to tort law, distributive justice to contract, and so on. Rather, our institutional practices are sensitive to a range of social facts that shape them. Wrongful losses can arise for all sorts of reasons; therefore, nullifying them by tort is a good idea generally. Other kinds of wrongful losses, however, can arise from breach of promise, and those are best dealt with under some other area of the law such as contract. To șay that tort law embodies an ideal of corrective 
so conceived, specifies grounds of recovery and liability; it does not specify a particular mode of rectification. It does, however, constrain the set of possible modes of rectification. Wrongful gains and losses cannot be annulled to create other wrongful gains or losses. Thus, any mode of rectification that does not create wrongful gains and losses is compatible with corrective justice; and any mode of rectification that creates wrongful losses violates corrective justice.

Only wrongful losses fall within the ambit of corrective justice. Therefore, any conception of corrective justice requires a substantive account of wrongfulness. Wrongful losses must be annulled, and the threat of creating new ones restricts the institutions we might develop for rectifying existing ones. Indeed, different conceptions of wrongfulness identify different losses as wrongful and different institutional mechanisms as permissible modes of rectification. For example, if it is wrongful to impose a loss upon those who do not agree to have the loss imposed upon them, then whenever someone injures a person who has not assumed the risk or otherwise consented to injury, the victim has suffered a wrongful loss deserving of repair. The victim's loss can be rectified in any way that does not create a wrongful loss. Imposing the loss upon anyone other than those who agree to bind themselves would be impermissible. Of course, injurers or wrongdoers may not agree to bind themselves, and, if they do not, imposing liability upon them would violate corrective justice. This may be one reason for rejecting the view that involuntariness of a loss is a sufficient condition of its being wrongful.

In contrast, if a loss is wrongful only if it results from inefficient conduct, many victims who have not agreed to accept certain risks or to have losses imposed upon them may have no claim in corrective justice to repair. If someone does have a legitimate claim in justice to repair, any mode of rectifying it would be permissible provided that liability could be justified on efficiency grounds. Imposing the victims' losses on the cheapest-cost-avoiders, for example, would be permissible even if cheapestcost-avoiders have not agreed to bind themselves, indeed, even if they are in no other way responsible for the loss in question.

As I have characterized it, the annulment thesis strictly prohibits institutions from rectifying wrongful gains and losses in ways that create additional wrongful gains and losses. On its face, this constraint may be too strong. Suppose a very substantial loss could be rectified by creating a rather minor one. Can corrective justice really mean to prohibit implementing an arrangement that would reduce the extent of wrongful losses in the world simply because the arrangement may occasionally require the imposition of another wrongful loss? Should not corrective justice look at both sides of the loss equation?

If corrective justice requires rectifying wrongful losses, but prohibits doing so if it creates other wrongful losses, then corrective justice may

justice is not to say that all and only wrongful gains and losses are rectified within it. Tort law is, in my view, especially concerned with rectifying wrongful losses. It is a further question, but not one strictly speaking of moral or legal philosophy, as to why tort law is not a particularly good institution for rectifying wrongful gains. 
permit considerable wrongful loss. On the other hand, if corrective justice permits the imposition of wrongful losses in order to eliminate even greater losses, then at least it minimizes the total amount of corrective injustice in the world. Which is the proper way of understanding the demands of corrective justice? ${ }^{12}$

One problem with imposing corrective injustices in order to annul greater wrongful losses is that it threatens to turn corrective justice into a form of efficiency. Thus, rather than saying that justice requires eliminating wrongful gains and losses as such, we are really advocating minimizing the extent of corrective injustices as a whole. The underlying economic principle consists of minimizing the sum of " $x$ " and the costs of reducing " $x$," where " $x$ " is replaced by "corrective injustice." Thus, one who has suffered a wrongful loss at the hands of another has no claim in justice to repair, as such. Instead, like everyone else, that person is entitled to the least corrective injustice in the world. This means the injured is entitled to repair in a particular case only if the compensation is "corrective-injustice minimizing," but not otherwise.

Within the annulment thesis, there is a way of responding to this problem that both allows us to treat claims in corrective justice adequately and to impose some corrective injustices in order to eliminate significant ones. First, it is always wrong to create a corrective injustice in order to rectify a wrongful loss if it is possible to correct the loss without doing so. Second, one can reject the claim that corrective injustice ought to be minimized. Instead, one might hold that it sometimes is permissible to impose a wrongful loss in order to eliminate another wrongful loss only if there is a substantial or significant difference between the loss eliminated and the loss created. Thus, advocates of the annulment thesis can reject the "optimizing" conception of corrective justice. While they admit that sometimes it is permissible to impose wrongful losses in order to annul other wrongful losses, they reject the marginalist form of reasoning about when doing so is permissible.

However plausible or intuitive this solution is, nothing I have said so far represents a defense of it. Moreover, I have no intention of providing the needed defense here, other than by analogy. The analogy concerns the way we normally think about rights and claims based on rights. Claims based on rights can be defeated by considerations, say, of utility. But part of what it means to have a right-part of its syntax-is that the claims based upon rights cannot be defeated by mere marginal increments in utility. The claim of right establishes a "significance" threshold. The gain in utility must be substantial before the claims of rights are overcome or defeated.

Thus, one can accommodate claims of rights and utility in a way that does justice to both. On the other hand, if claims of marginal advantage could defeat claims based on rights, we could not say that people really had rights; rather, we would be optimizers or utility maximizers with no real account of rights. That is one reason, for example, David Lyons has denied

12. See infra, A Mixed Conception of Corrective Justice, at Part IV. 
that there can be a utilitarian theory of rights. ${ }^{13}$ Utilitarians are committed to incrementalist reasoning in a way that is incompatible with the significance threshold entailed by rights.

Something similar, I am suggesting, is true of claims to repair in corrective justice. Corrective justice specifies grounds, not modes, of rectification. It constrains modes of rectification to the extent that it does not normally permit the creation of wrongful losses as a way of eliminating other wrongful losses. On some occasions, however, when no other alternatives are available and the difference between the loss created and the loss eliminated is sufficiently great, corrective justice may permit the creation of what would otherwise be a wrongful or unjust loss. ${ }^{14}$

As I have stated it, the principle of corrective justice appears to hold that justice consists entirely in creating a certain state of the world in which wrongful gains and losses are annulled. From the point of view of justice, it seems that each of us has the same responsibility to bring about that state. In other words, corrective justice so understood, gives no one in particular any special reason for acting.

Suppose we hold that justice and morality are guides for action. Thus, principles of justice and morality do not simply provide answers to metaphysical questions, ${ }^{15}$ they give agents reasons for acting. Their importance depends on their role in practical reasoning. One way in which corrective and distributive justice might differ, then, is with respect to the ways in which they figure in an individual's practical reasoning. Corrective and distributive justice are distinct principles of justice. They give individuals different kinds of reasons for acting. This is not how corrective and distributive justice differ in the annulment view, however. As I characterized it, the annulment view appears to hold that justice requires a certain state of the world be brought about, but no one in particular has a special reason in justice for bringing it about. This is precisely the way we think about distributive justice. Therefore, in terms of their reason-giving properties, corrective justice is indistinguishable from distributive justice.

13. David Lyons, Utility as a Possible Ground of Rights, 14 Nous 17 (1980).

14. A further question asks how we can talk about greater or lesser wrongful losses. You injure me wrongfully causing $\$ 100$ in losses. This is the wrongful loss I suffer. Suppose you are judgment proof, and there is no way of shifting the loss to you. We have to shift it to someone else. Could it ever be less of a wrongful loss to shift it to someone else? Would not it always be a $\$ 100$ wrongful loss? That depends on how we analyze the notion of a wrongful loss. Some might suggest that if we impose the loss on someone other than the injurer through the machinery of the state, it is a greater wrongful loss simply because the state is imposing the cost or because it is being imposed on someone who had nothing to do with the original interaction. If the cost is imposed on someone unsavory then some might argue that the injustice is a lesser wrong than imposing it on the innocent victim. Everything hinges on how we analyze the components or elements of wrongful loss. Another possibility is that the victim suffers the damage of $\$ 100$, but receives no offsetting benefit. On the other hand,'imagine some third party who, as a result of the injury, is benefitted $\$ 50$. If the victim's loss is shifted to that party, we might say that the victim would suffer only a $\$ 50$ wrongful loss instead of $\$ 100$. We subtract the third party's benefit-wrongful or not-from the $\$ 100$ loss we impose upon the third party.

15. One view of moral principles is that they answer metaphysical questions, not problems in practical reasoning. In other words, rather than providing us with reasons designed to guide our actions, they tell us which acts, persons, or social states are good, right, and the like. 
At the outset, I suggested one might appeal to corrective justice in ways that might sustain distributive injustices. That means that corrective justice must be distinct from distributive justice. We have just suggested, however, that if corrective justice is understood in terms of the annulment thesis, it creates reasons for acting in the same way (and of the same type) that distributive justice does. If the difference between the two is to be reflected in terms of the reasons for acting each creates, the annulment view appears unable to distinguish corrective from distributive justice. It would fail, therefore, as a defensible conception of corrective justice.

An example illustrates the basic problem. If Josephine steals Ronald's radio, then Josephine has a reason to act under corrective justice that neither you nor I have. Neither of us has a responsibility to see that Ronald's radio is returned or, if it is damaged, that he is compensated. Rather, Josephine has a reason for returning the radio that none of us has. The same would not be true with respect to our duties to Ronald in distributive justice. If distributive justice required that certain needs of Ronald's be met, then each of us would have the same kind of reason under justice to see to it that those needs were met.

If corrective justice provides individual agent-relative reasons for acting in this sense, it cannot be a principle that provides only grounds for claims to recovery and liability. It must be a principle that specifies individual rights and responsibilities. And if it specifies a system of correlative rights and responsibilities, it also specifies a particular mode of rectification. Those who possess the duty in corrective justice to make repair must be made liable in justice to do so. Any other scheme of liability offends justice. Josephine's wrong is taking Ronald's radio; corrective justice imposes the duty upon her to return it or, if she has ruined it, to replace it. No one else in corrective justice has the same reason for acting as Josephine does; no one must do what she must do.

The annulment view faces two general, but related problems. First, it seems unable to account for the distinction between distributive and corrective justice. Second, it provides only grounds for recovery, whereas a proper conception of corrective justice will specify a mode of rectification as well as a reason for doing so. Rectification in corrective justice will be the duty of someone in particular. This suggests that the annulment view must be augmented or abandoned. Before considering an alternative to it, let us develop these objections to the annulment more fully in the hopes of establishing their ultimate persuasiveness.

\section{The Relational Conception of Corrective Justice}

Until recently, I believed that the annulment thesis provided the only plausible interpretation of corrective justice. Joseph Raz, ${ }^{16}$ Ernest

16. Professor Raz has influenced my view largely through conversation. See A Symposium, The Works of Joseph Raz, 62 S. Cal. L. Rev. 731 (1989). 
Weinrib, ${ }^{17}$ and especially, Stephen Perry ${ }^{18}$ have convinced me that the annulment thesis is untenable. The annulment thesis does not provide anyone with any special reason for acting. If someone has suffered a wrongful loss then that loss should be eliminated. But how and by whom? The answer implicit in the annulment view appears to be: it depends. Justice itself does not tell us who should do what to repair the damage. Instead it warns us against rectifying the loss in any way that creates additional wrongful loss. This feature of the annulment thesis reduces corrective justice to a form of distributive justice. This is the line of argument suggested above. Let us develop it in somewhat greater detail.

In one view of distributive justice, we all have reasons for acting in certain ways for providing each member of the community with whatever the principle of distributive justice requires. This responsibility falls on each of us, but coordination in efficiently discharging this duty is difficult. Therefore, we create a larger institution, the state, which acts as our agent and ensures that we discharge our obligations under distributive justice. ${ }^{19}$

We have other responsibilities to one another that are not matters of distributive justice; they are owed by us to other persons as a result of actions we undertake and relationships we form. Some of these duties are contractual and result from commitments of one sort or another. Others arise from the advantages we take of one another or the harms we occasion. So if I take your watch, I alone have a duty to return it. If I somehow destroy it, then I alone owe you compensation.

Perhaps if I take all your possessions, you will fall below the social safety net. Everyone has a responsibility to see to it that people are situated above the safety net. I now have two connected responsibilities: one to return what I have taken; the other to see to it that you rise above the safety net. I can discharge both by returning your possessions. If I do not, then you are below the safety net and the duties of others under distributive justice apply. Each person has a duty to see to it that you rise above the safety net, which might entail working to get me to return your possessions, or failing that, to see to it that you are compensated for your loss. Usually that duty will be discharged by the state through welfare or other forms of social insurance. But the state is merely acting as our agent in discharging our duties under distributive justice.

Notice that the duty each of us has in distributive justice to compensate you is triggered only when you fall below whatever distributive justice claims is your entitlement. No one is responsible to make good your loss. Only the injurer, that is me, is required to return your possessions or make good your losses independent of considerations of distributive justice. Only I have a duty to return or repair in corrective justice. That is the essential point of

17. See Ernest J. Weinrib, Toward a Moral Theory of Negligence Law, 2 Law \& Phil. 37 (1983).

18. Professor Perry has influenced my view in numerous conversations. See Perry, supra note 7.

19. For similar coordination-related reasons, we may empower this state to do other things as well, like provide public goods. 
what I call the "relational conception of corrective justice." It is a point whose difference with the annulment theory is worth emphasizing.

In the annulment thesis, wrongdoing creates no special reason for the wrongdoer to act. Rather, the focus appears to be entirely on the victim's loss. That loss should be annulled. In general, we have interests in the well-being of victims and are sensitive to shifts in their wealth. Should they suffer a diminution in welfare because of a flood, a hurricane, or some other misfortune, then we might feel that their loss is undeserved and should, if possible, be eliminated. The losses they suffer at the hands of others are also of this sort. They are losses that are undeserved and should, if possible, be eliminated. In the same way that losses owing to misfortune create grounds for annulment, so too do losses owing to the wrongful mischief of another. If the argument for eliminating losses in one case is beneficence, then so too is the argument for doing so in the other. If it is our responsibility in distributive justice to eliminate losses owing to natural disasters or undeserved handicaps, then the argument that brings wrongfully inflicted losses to our attention is also one in distributive justice. Losses owing to wrongdoing are among the set of losses that generally ought to be eliminated.

The problem for the annulment view is that corrective justice provides particular persons with reasons for acting, and it is that fact that distinguishes corrective from distributive justice. Without the imposition of a duty or responsibility, corrective justice is reducible, at best, to one or another form of distributive justice. That seems to be an implication of the annulment thesis. To wit, wrongfully-imposed losses are among the losses that should be compensated, but, arguably, so are losses that result from handicaps, natural disasters, and misfortunes generally.

In the annulment view, the point of corrective justice is to eliminate or rectify certain gains and losses. It says nothing about who has this duty, if anyone does, in justice. The alternative conception of corrective justicewhat I call the "relational view"-makes exactly the opposite claim. It denies that corrective justice has any point or purpose with respect to the category of gains and losses. The existence of a loss is not necessary to trigger corrective justice, nor is the point of corrective justice to annul or eliminate the loss. Rather, it specifies a framework of rights and responsibilities between individuals. In the relational view, it is the wrong, not the loss that must be annulled. The relational view claims, in effect, that corrective justice operates on relationships between persons. If one person has wronged another, then corrective justice imposes a duty on the wrongdoer to rectify his wrong. In the annulment thesis, in contrast, the fact that one person wrongs another creates a state of the world that is the concern of justice, but perhaps not of anyone in particular, including the wrongdoer. In the relational view, the fact that one person wrongs another affects the system of rights and responsibilities between them.

There are two important differences between the annulment and the relational views. In the annulment view, corrective justice is triggered by wrongful losses. Its point or purpose is to eliminate or rectify losses (and gains). In doing so, it does not appear to impose the responsibility to annul on anyone in particular. In contrast, wrongful losses are of no direct 
consequence in the relational view. Corrective justice has no point or purpose, let alone the specific purpose of annulling them. Moreover, in the relational view, corrective justice establishes a scheme of responsibilities and rights. Thus, unlike the annulment thesis, the relational view creates specific, agent-relative reasons for acting.

It is important to distinguish the relational view from other conceptions of corrective justice with which it might be confused. Richard Epstein, for one, appears to hold that justice requires that the individuals causally responsible for the losses of others be held liable in order to make those losses good.$^{20}$ If I understand his position correctly, Epstein shares with the annulment thesis the view that the point of corrective justice is to eliminate wrongful losses. His view differs from the annulment thesis in holding that such losses ought to be eliminated by imposing liability on particular wrongdoers. The annulment view is agnostic with respect to liability for loss. It shares with Epstein, however, the view that the normatively significant aspect of the relationship between persons from the point of view of corrective justice is the existence of wrongful losses.

Though the relational view appears similar to Epstein's position, in fact it denies both of Epstein's central tenets. In the relational view, wrongful losses as such are normatively unimportant. Their existence does not trigger the application of the principle, nor is it the point of the principle to eliminate or rectify wrongful losses. Rather, the fact that someone wrongs another creates the relevant duty in corrective justice. Losses have nothing to do with it. Moreover, while Epstein believes that losses should be annulled by imposing liability upon particular wrongdoers, ${ }^{21}$ the relational view does not assert that there is only one institutional form through which the debts under corrective justice can be discharged. Thus, while the relational thesis rejects annulment as the point of corrective justice, it accepts the distinction between the claims of corrective justice and the institutional forms available for satisfying them. In this regard, it is similar to the annulment thesis.

Because the relational view is concerned entirely with the ways in which wrongdoing alters individual rights and responsibilities, it is possible to confuse it with attempts to embed corrective justice in a particular account of what it is to have a right, and in doing so to provide a conceptual foundation for corrective justice. Providing a foundation for the relational conception of corrective justice is important because it is unclear why corrective justice has no goal beyond identifying the ways in which wrongdoing alters the normative relationships among agents. The relational view merely imposes a scheme of rights and responsibilities. One reason it does, one might argue, follows from our understanding of what it is to have a right. Corrective justice, in this view, is simply part of the meaning of rights.

Suppose we analyze rights in the following general way. For instance, to say that you have a right that I not harm you, is to say that I have a duty

20. See supra note 3 .

21. See supra note 3. 
not to harm you. These are correlative rights and duties that are primary or fundamental to the content of the right in question. However, for you to have such a right means that you have a variety of secondary rights as well; these are, or can include, metarights-rights about your primary rights. One such right is that I compensate you in the event that I invade or violate the first-order right of not harming you. Similarly, we might say that I have a series of second-order duties correlative of your second-order rights, and among these, presumably, is the right that I compensate you if I fail to discharge my first-order duty not to wrong you. Thus, when I harm you in a way that violates your first-order right, you have a second-order right against me to repair the resulting damage and I have a corresponding second-order duty to provide it.

This argument, which purports to provide a conception of corrective justice, in fact does not mention corrective justice at all. Instead, the argument draws its conclusions from a particular account of what it is to have a right. The connection between secondary and primary claims or rights clearly relies on normative, not analytic, considerations. Even if we accept the view - which I do not-that correlative of every right is some specifiable set of duties, and that rights are to be analyzed in terms of the connection between or among the rights and duties, it hardly follows that the existence of certain primary rights entails, in any sense, the particular list of secondary rights or claims that includes the claim to repair. The right not to be harmed can be protected in any number of ways, each of which may give rise to very different secondary claims, and some of which may give rise to no secondary claims at all. Surely, how we should secure or protect the important interests marked by rights is not a matter of logic, but a matter of substantive moral argument.

If the duty to compensate and the right to compensation do not follow as a matter of logic from the nature of what it means to have a right, but follow instead from a suitable normative principle, from which principle do they derive? The obvious choice is the principle of corrective justice. In other words, the duty to compensate and the right to compensation for the invasion of rights derives from the principle of corrective justice. Or to put the matter somewhat differently, the second-order right to repair and the corresponding duty to compensate are ways in which the principle of corrective justice requires that first-order rights be protected and duties enforced. The principle of justice, however, does not derive from a plausible theory of rights. Instead, it is the moral principle external to rights that gives rights a certain content; it is an element of an underlying foundational theory of rights, not part of the meaning or syntax of rights. In other words, we cannot defend a particular conception of corrective justice by showing that it follows from our understanding of what it is to have a right when it is that conception of corrective justice itself that grounds that understanding of what it is to have a right. One thing we might say about the relational conception of corrective justice is that it grounds a particular conception of what it is to have rights of a certain kind.

\section{A Mixed Conception of Corrective Justice}

The annulment conception of corrective justice runs into trouble because it seeks only to articulate grounds of repair. As such, it does no more 
than identify a category of losses about which something ought to be done. In the limit, the focus on the wrongfulness of the loss as such obliterates the distinction between corrective and distributive justice. This is one objection the relationalists press against me. The other objection is that by focusing on the loss as my previous work does, my account provides no explanation of how corrective justice gives rise to reasons for action in some agents but not in others. To illustrate, consider the radio example. If Josephine takes Ronald's radio, then corrective justice gives Josephine a reason for acting that no one else has. She has a duty to return it or repair the damage, a duty no one else has.

These objections have convinced me that the annulment thesis is inadequate. Here, I provide a new conception of corrective justice that accommodates both the relational and the annulment conceptions of corrective justice. I do not want to claim that this conception satisfies every objection leveled against my previous work; nor do I believe that the changes in my view will delight, rather than disappoint, those who have followed me in analyzing corrective justice in terms of annulment or rectification only. I claim only to provide a plausible conception of corrective justice that is closer to the truth of the matter than anything I have previously defended.

The central insight of the relational view I want to incorporate is that there is a difference between reasons for acting we have as a result of our actions, and reasons we have by virtue of our being members of a particular community. As a citizen of the United States, I have reasons for seeing to it that others are adequately housed and clothed. On. the other hand, if I promise to meet you for lunch, then I have a reason for acting that I did not have before I promised to eat lunch with you. This reason is one I might not have had if I had not so promised, and one which no one else may have. My act of promising creates the reason for acting. In the same way that promising can create reasons for acting, my harmful or wrongful actions also can create reasons for acting. If I negligently injure you, I may have reasons to act that I would not have had prior to injuring you and reasons to act that others who have not injured you very likely do not have. In the case of promising, the reasons to act derive from the accepted conventions governing the practice of promising. In the case of my negligently injuring you, the reasons for action and their content derive from the principle of corrective justice. I accept the relational view's emphasis on the way in which corrective justice creates special reasons for acting in persons as a consequence of their actions.

Wrongs are invasions of rights. In the relational view, corrective justice requires that wrongs be annulled by imposing a duty to repair on the right-invader. Understood in this way, the relational view denies the normative relevance of wrongful losses as providing a ground as well as the content of the duty in corrective justice. This feature of the relational view is unacceptable. Instead, I defend the aspect of the annulment thesis that emphasizes wrongful losses both as an aspect of corrective justice and as part of its point. Thus, I articulate and defend what I call the "mixed conception" of corrective justice. 
Let us begin by stating precisely the relational conception of corrective justice. Corrective justice imposes a duty, but what duty? It imposes the duty by virtue of something a person does, but what is that something that creates the duty? In the conventional interpretation of the relational view, it is the fact one has done something wrong that triggers corrective justice. Corrective justice then operates on the action performed to create and to impose a duty that would not otherwise have existed. It is a duty to correct or to annul. Correct or annul what? It is a duty to correct or annul that which one did that triggered corrective justice in the first place, namely the wrong. Thus, a natural understanding of the principle of corrective justice is that corrective justice imposes the duty to repair the wrongs one does.

The relational view emphasizes the wrong one does and not the losses that might result as a consequence. The duties one has in corrective justice arise as a result of wrong or wrongdoing, not as a result of wrongful loss. The duty then is to repair the wrong. What then is the connection between repairing the wrong (or wrongdoing) and repairing the loss? Indeed, the problem with the relational view is that it cannot take us from "repairing the wrong" to "repairing the loss." Moreover, if repairing the loss is not part of corrective justice, then what can the point of corrective justice be? If repairing the wrong is unconnected with repairing the losses it occasions, corrective justice may well leave innocent victims without visible means of claiming compensation in justice. In that case, corrective justice may have nothing to do with tort liability for loss, a practice whose point of departure is the victim's loss.

To illustrate the problem facing the relational view consider an example. Suppose Steven negligently rams his car into David causing $\$ 1,000$ in damages. The annulment thesis holds that David has suffered a wrongful loss that needs to be eliminated; it then asks whether the best way of doing justice in this case would impose the loss on Steven or somebody else. What does the relational view say? First, it notes that what Steven has done constitutes a wrong. Second, it holds that as a result Steven has incurred a duty to repair his wrong. The problem is figuring out what the wrong is; only then can we figure out what needs to be done in order to repair it.

To focus the discussion further, suppose Michelle drives negligently in the same way Steven did, but Michelle's negligence causes no damage. In one view, Steven's wrong was his negligent driving and putting people, including David, at risk. The negligence is the wrongdoing that needs to be repaired. Michelle is a wrongdoer in precisely the same way and, we might suppose for the argument, to the same extent. Each has a duty to repair the wrong each has done. ${ }^{22}$ We can imagine some plausible ways in which both can repair the wrong they have done. Steven and Michelle must apologize to those they put at risk. Or, they must make a public statement conveying the judgment that they were wrong to treat others as means to their ends.

22. I am not altogether clear about how the wrong is supposed to be repaired, and am even less clear about how it is to be annulled-especially if the duty to annul is supposed to be understood in Hegelian terms. 
Or perhaps the only way of annulling the wrong is to imprison them or otherwise to subject them to expressions of public indignation and disapprobation.

But what are we to say about David's $\$ 1,000$ loss? One thing we might say is that repairing the wrong does not involve repairing the loss. In that case, David is out of luck. Or we might say that his "wrongful loss" is the concern of distributive, not corrective justice. In that case, we might rectify or eliminate his loss through funds raised from the state treasury. Alternatively, we might say that Steven's wrong includes the loss he imposed upon David. Thus, Steven's wrong is different from Michelle's. Repairing his wrong would involve both apology and compensation, whereas repairing hers would require apology only.

The claim that Steven's wrongdoing is different than Michelle's only because David suffers a loss as a consequence of his mischief begs the question. What principle makes David's loss part of Steven's wrongdoing rather than an untoward consequence of it? What did Steven do that Michelle did not? Each drove negligently, that is, wrongfully. What differs is the consequences of the wrong, not the wrong itself.

Instead of arguing that Steven's wrong differs from Michelle's simply because the consequences of their mischief differ, we might argue that even though the wrongs are the same, the content of the duty to repair the wrong differs because the consequences of their mischief differ. Both have done the same wrong; they have driven negligently. Both, therefore, have the same duty under corrective justice; each has the duty to repair the wrong. To annul a wrong is to eliminate its effects in the world-as much as is feasible. That is to say that annulling a wrong returns the world to where it would have been had the wrong never been committed. In this sense, to repair fully the wrong is to repair not only the wrong, but its consequences as well. That would mean giving up whatever gains one has secured as a result of the wrong as well as compensating for whatever damage one has caused others to suffer. Though Michelle and Steven have committed the same wrong, this account of what it means to annul or repair a wrong explains why Steven and Michelle have different duties in corrective justice as the result of committing the same wrongful act. Steven's duty to compensate David is a matter of corrective justice because it is part of what Stephen must do to repair his wrong. It is part of what he must do to make the world as if his wrong had never occurred within it. Michelle's negligence harms no one; repairing her wrong does not require her to compensate anyone. Thus, the same wrong can yield different concrete duties under the same abstract duty to repair that wrong.

More importantly, this account explains why Steven must compensate David in corrective justice without making the fact that David has suffered a wrongful loss part of the reason-let alone all of the reason as in the annulment view - for having to do so. The wrongfulness of the loss has nothing to do with the nature of Steven's duty. Repairing the wrong means making it as if the wrong had never occurred; that means compensating the victims. This, I take it, is how the pure relational view ultimately would deal with the appropriateness of the damage remedy. 
The problem with this account of the relationship between the wrong and the resulting losses is that it is based on an unacceptable understanding of what is required in order to "repair" or annul a wrong. For example, suppose I am scheduled to take a plane from New Haven to Washington and I take a taxi to the airport. The taxi driver is drunk and drives recklessly as a result. Five blocks from the airport, the taxi hits another car. My leg is broken; I am taken to the hospital and I miss my flight. The plane I would have taken crashes. There are no survivors. Had I caught the plane, I would have died. Only the taxi driver's recklessness kept me alive.

There is no doubt that the taxi driver acted wrongfully and, as a result, incurs a debt under corrective justice to repair the wrong committed. But if we understand repairing the wrong in the way we do in Steven's case, then the taxi driver has a duty to make the world as if his wrong never happened. In that world, I would have died in a plane crash; my being alive is a consequence of his wrong-one for which I am grateful. But can the taxi driver really have a duty to bring about my death? I do not see how he could. The duty to repair is not the duty to annul all the consequences of one's wrongs. It is, I suggest as a first approximation, the duty to repair the wrong-in whatever sense we can ultimately make of that phrase-and all the wrongful consequences of it. The gist of my suggestion is that the wrongfulness of the loss is an independent aspect of corrective justice, independent of the wrong or wrongdoing itself. Thus, repairing the wrong and repairing the wrongful losses occasioned by it can be distinct duties under the principle of corrective justice. If I was wrong in my earlier work to focus entirely on the wrongfulness of the loss as the point of corrective justice, then I would commit a greater error by accepting the pure relational view that treats the loss as only coincidentally connected to the duty to repair.

These considerations suggest the following characterization of what I call "the mixed conception of corrective justice." Corrective justice imposes on wrongdoers the duty to repair their wrongs and the wrongful losses their wrongdoing occasions. The duty to repair the wrong follows from the relational view; the importance of wrongful losses to the demands of corrective justice is a remnant of the annulment view, thus, the "mixed" view. This conception of corrective justice needs further amendment, however. Repairing the wrong itself, the cornerstone of the relational view, is not part of corrective justice at all. The view I defend is that the duty of wrongdoers in corrective justice is to repair only the wrongful losses for which they are responsible.

\section{A Wrong is not Always Wrong}

There are two problems with the notion that corrective justice requires annulling wrongs. First, the wrongs that typically concern corrective justice are not wrongs in the sense that usually calls for annulment. Second, to the extent individuals commit such wrongs, principles of justice designed to deal with them already exist. In the typical case, an injurer is at fault for failing to exercise the care that a reasonable person of ordinary prudence would have exercised. Judgments of this sort are not ordinarily defeasible by what we would think of as an excuse. In the typical case, the fault or wrong is in the doing, not in the doer. The agent need not have done 
something which calls for blame, something that displays a lack of proper motivation or a defect in character. The wrongdoing is objective. Similarly, wrongs that are invasions of rights need not be culpable in the ordinary sense. In the infringement cases, these wrongs result from conduct that is on balance justified and not culpable at all. Excusable conduct can be at fault; justifiable conduct can be rights-invasive and constitute a wrong.

The wrongs that fall within the ambit of corrective justice often do not mark a moral defect in the agent or in the agent's action. It is hard to see why annulling them would be a requirement of justice. On the other hand, some cases of genuine wrongdoing mark a fault in the agent and in the action. The reckless imposition of unjustifiable levels of risk and the intentional harming or injuring of another are genuine wrongs. A case could be made that justice requires annulling them. But there already is a principle of justice which holds that such wrongs should be annulled: the principle of retributive justice.

Annulling moral wrongs is a matter of retributive justice, not corrective justice. There exists a legal institution that, in some accounts, is designed to do retributive justice through punishment. The bulk of cases in which claims in corrective justice are valid do not involve wrongs in this sense. If we abandon the view that corrective justice requires annulling certain wrongs, we are left with the claim that corrective justice imposes a duty on wrongdoers to annul the wrongful losses their conduct occasions.

Does this mean that we have returned to the annulment thesis, that we have given up the relational view altogether? No. Corrective justice imposes on wrongdoers the duty to repair the wrongful losses their conduct occasions. Thus, it provides wrongdoers with reasons for acting that are peculiar to injurers in an agent-relative sense; to annul losses for which they are responsible. The insight of the relational view is that wrongdoing changes the nature of the relationship between the parties; it creates duties where none previously existed. It gives agents reasons for acting that they did not previously have. The problem with the relational view is that it misinterprets the content of the duty. The annulment thesis correctly interprets the content of the duty. Thus, we have the mixed conception of corrective justice.

In the relational view, the fact that wrongdoers do something wrong gives them a duty to repair that wrong. In the mixed view, wrongdoers have no duty to repair the wrong. Instead, they have a duty to repair the wrongful losses that are their responsibility. What grounds that duty? It is not the fact the injurer has done something morally blameworthy or otherwise culpable-something, in other words, that in fact might ground a duty to right the wrong. The wrong or wrongdoing the injurer has caused is relevant because it renders the losses caused wrongful. Without wrong or wrongdoing, there may be losses, but they are not wrongful. The duty to correct the losses derives not from the agent's having done wrong as such, but from the losses being in an appropriate sense the agent's responsibility. They are the consequences of agency: the agent's causal powers. They are 
his fault. ${ }^{23}$

The argument has two parts. First, the losses are the concern of corrective justice only if they are wrongful. They are wrongful if they result from wrongs or wrongdoings. The wrong does not ground the duty to repair. Rather, it grounds the claim that the losses are wrongful and thus within the ambit of corrective justice. Secondly, the duty to repair those wrongful losses is grounded not in the fact that they are the result of wrongdoing, but in the fact that the losses are the injurer's responsibility, the result of the injurer's agency. ${ }^{24}$ The duty to repair a loss under corrective justice is grounded in the injurer's connection to that loss. They are, in a suitable sense, the injurer's responsibility; they are the injurer's, and therefore, are the injurer's to repair.

\section{Grounds and Modes of Recovery Revisited}

I previously have argued that under the annulment thesis there is a difference between the grounds and modes of rectification. ${ }^{25}$ The question is whether the distinction is applicable to corrective justice as I now understand it. In the mixed conception, corrective justice provides both a grounds for liability and recovery and a reason for claiming that compensation is someone's moral duty. Thus, one might be tempted to hold that the principle of corrective justice provides both the grounds and the mode of recovery. That wrongful losses ought to be annulled means that victims have a right to repair; and because wrongdoers have a duty to repair in corrective justice, the proper mode of rectification is one that imposes liability for those costs upon them. In that case, any mode of rectification other than imposing the victim's costs on the injurer would violate corrective justice. Is this constraint on liability entailed by the mixed conception of corrective justice?

Even if the injurer has the duty to repair in justice, it does not follow that justice requires that the duty be discharged by the injurer. We need to distinguish between the grounds of the duty and the institutional mechanisms that are permissible ways of implementing the duty. For example, the duty to repair is a debt of repayment. People who take out loans incur debts of repayment. We might even say that these are debts in justice. But it does not follow that an injustice is done whenever someone other than the indebted individual repays the debt. So if Donald Trump decides to repay all my debts (for which I would be suitably grateful), and does so (for which I would be even more grateful), all claims against me would thereby be

23. An agent, $S$, is responsible for a wrongful loss, W, only if W is S's fault. W is S's fault only if: (1) $S$ is at fault; (2) W results from an aspect of S's conduct that is at fault; (3) the loss falls within the scope of reasonable foreseeable risk in virtue of which that aspect of S's conduct is at fault. This analysis defeats the objections mistakenly raised against my account by Weinrib and Wright.

24. If we inquire further, and want to know why responsibility or causal power are necessary to impose a duty to repair, the answer is even more tentative. It is through the exercise of the powers of autonomous agency that individuals make their mark in the world. It is through their actions that we come to understand individuals, and more importantly, it is through our actions that we come to our own self-understandings.

25. See supra note 11 . 
extinguished. If the loans are repaid by someone other than me, no injustice has been done. This is true even if it is me, not Donald Trump, who has the duty in justice to repay the debts. This is true, moreover, even if Trump does this all on his own, without any encouragement from me, or in the absence of a contractual or other understanding between us.

This example illustrates that someone other than the indebted party can discharge the duty without constituting an injustice. Therefore, it does not follow from the fact that one is required to make repair as a matter of corrective justice that any institutional arrangement, or mode of rectification, which discharges that duty in some other way (for example, through the general tax coffers) would be unjust. The question to consider is: what modes of rectification are compatible with the mixed conception of corrective justice?

\section{Conclusions}

I have distinguished among three conceptions of corrective justice: the annulment view, the relational view, and the mixed conception. The annulment view holds that wrongful gains and losses ought to be annulled. It does not specify by whom. It does, however, treat the existence of certain gains and losses as determining its domain and purpose. In contrast, the relational view holds that individuals who do wrong (or wrongdoers) have a duty to repair the wrong. It selects the person who has the duty; indeed, its entire point is to create the agent-relative duty. In the relational view, however, wrongs and not losses (or gains) are its domain and provide the content of the duty. The mixed view holds that individuals have a duty to repair the wrongful losses for which they are responsible. Like the annulment view, the mixed view treats the existence of wrongful losses as morally relevant to its purpose. Its point is to rectify them. To this end, however, it imposes the duty to repair on the person responsible for creating a wrongful loss. The relational view is correct to fault the annulment view for failing to connect the demands of corrective justice to individual reasons for acting. The annulment view is -correct to emphasize the moral significance of wrongful losses. The relational view misses this point entirely. The mixed view captures the important insights of both my previous view and its critics.

Nothing I have said here reaches three questions that remain: (1) What conception of wrong and wrongdoing is implicated in the mixed conception of corrective justice? (2) Does corrective justice permit the duties it imposes to be discharged by individuals other than those it encumbers? (If so, under what conditions?); and, (3) To what extent does modern tort law reflect or express the mixed conception of corrective justice? My purpose in this Essay has been the modest, but important, one of defending a conception of corrective justice. The next order of business will be to explore its limits and the extent to which it is reflected in our legal practices. ${ }^{26}$

26. These issues are more fully explored in Coleman, supra note *. 